\title{
Developing Catalysts and Catalytic Processes with Industrial Relevance
}

\author{
Hans-Ulrich Blaser*
}

\author{
Dedicated to Prof. Dr. Daniel Belluš on the occasion of his 70th birthday
}

Abstract: The catalysis group of Solvias has its roots in the Central Research Laboratories of Ciba-Geigy. Since the early eighties its research has been focused on three areas of catalytic technology: heterogeneous hydrogenation, coupling catalysis, and enantioselective hydrogenation. Today, these are still the catalytic methods with the greatest industrial potential. In this overview a short description will be given how these methods have been developed further since the spin-off of Solvias in 1999. It will be discussed which strategies were successful and what the most important results have been in the first decade of Solvias.

Keywords: Coupling catalysis · Enantioselective hydrogenation · Heterogeneous hydrogenation · Solvias

\section{Catalysis in the Fine Chemicals Industry - What it's All About}

Fine chemicals are still predominantly produced using stoichiometric organic methods. ${ }^{[1]}$ This is in strong contrast to the production of bulk chemicals which relies heavily on catalysis. The difference can be explained on the one hand by the higher complexity of fine chemicals which makes catalysis more demanding and on the other hand by the fact that process chemists are usually more familiar with sophisticated organic synthesis. Nevertheless, the application of selected catalytic methods has increased in recent years in part because both production costs and waste minimization are of growing importance, even for high-value pharmaceuticals, and also due to the new catalytic methods developed in academic laboratories which are now slowly finding their way into industrial laboratories.

At Ciba-Geigy, we found that only very few catalytic methods are actually applied on a regular basis. The most important ones are heterogeneous hydrogenation, coupling catalysis and homogeneous enantioselective hydrogenation with the successful methods sharing the following properties: They have a broad scope to make important structural moieties;

${ }^{*}$ Correspondence: Dr. H.-U. Blase

Solvias AG

P.O. Box

$\mathrm{CH}-4002$ Basel

Tel.: +41616866155

Fax: + 41616866311

E-mail: hans-ulrich.blaser@solvias.com

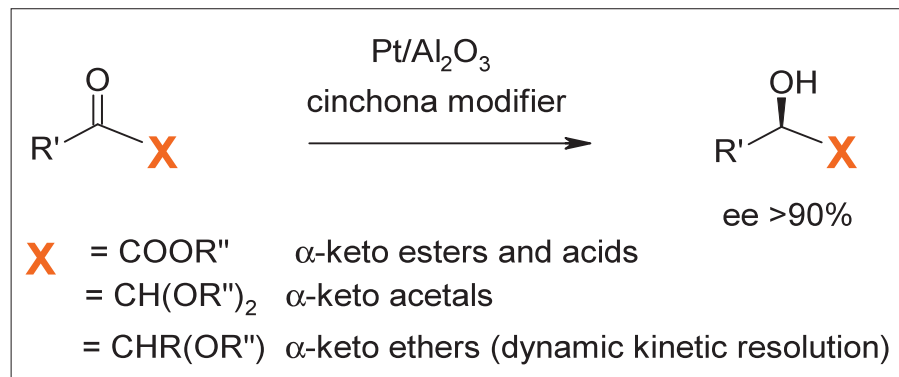

Scheme 1. Extended scope of the cinchonamodified Pt catalysts.

the catalysts are easy to apply and commercially available and, last but not least, process chemists 'believe' in the potential of the technology (success breeds success). During the years as part of the Central Research Laboratories, we were able to build a substantial basis of $\mathrm{R} \& \mathrm{D}$ results in all three areas and also implemented a number of significant production processes. An important factor for this success was the solid support by the management - not least among them by Daniel Belluš. In the following sections a brief outline will be given how the three fields were developed in the context of a small technology provider (as opposed to within a large integrated company) in order to enhance their industrial applicability. Obviously, such a company can only survive if it succeeds in convincing potential customers to use (and pay for) technology when this technology is capable of solving their problems with some guarantee for success within a reasonable time.

\section{Heterogeneous Hydrogenation - Revival of an Old Technology}

Heterogeneous hydrogenation is the most widely applied catalytic reaction in the fine chemicals industry. ${ }^{[1 a]}$ Indeed, over 34,000 different substrates have been hydrogenated since the start of the hydrogenation laboratory in the former Geigy in the 1930s. This technology received a new boost when it was discovered that modification of the classical catalysts could significantly improve their selectivity and indeed, our research efforts was concentrated on this approach. We had considerable success for the enantioselective hydrogenation of activated ketones ${ }^{[2]}$ and the chemoselective reduction of nitroarenes with other reducible substituents. ${ }^{[3]}$

While the early research in the area of the enantioselective ketone hydrogenation was focused on fundamental and mechanistic aspects of the cinchona-modified platinum catalysts, ${ }^{[4]}$ work at Solvias was dedicated to broadening the substrate scope and to synthetic applications. It was shown that besides the 'classical' $\alpha$-keto esters, substrates such as $\alpha$-keto acetals ${ }^{[5]}$ and ethers ${ }^{[6]}$ can also be reduced with high enantioselectivities, giving access to $\alpha$-hydroxy acetals and ethers which are valuable chiral building blocks (Scheme 1).

As depicted in Scheme 2, the optimized catalyst system was applied on a technical scale to an improved total synthesis of 

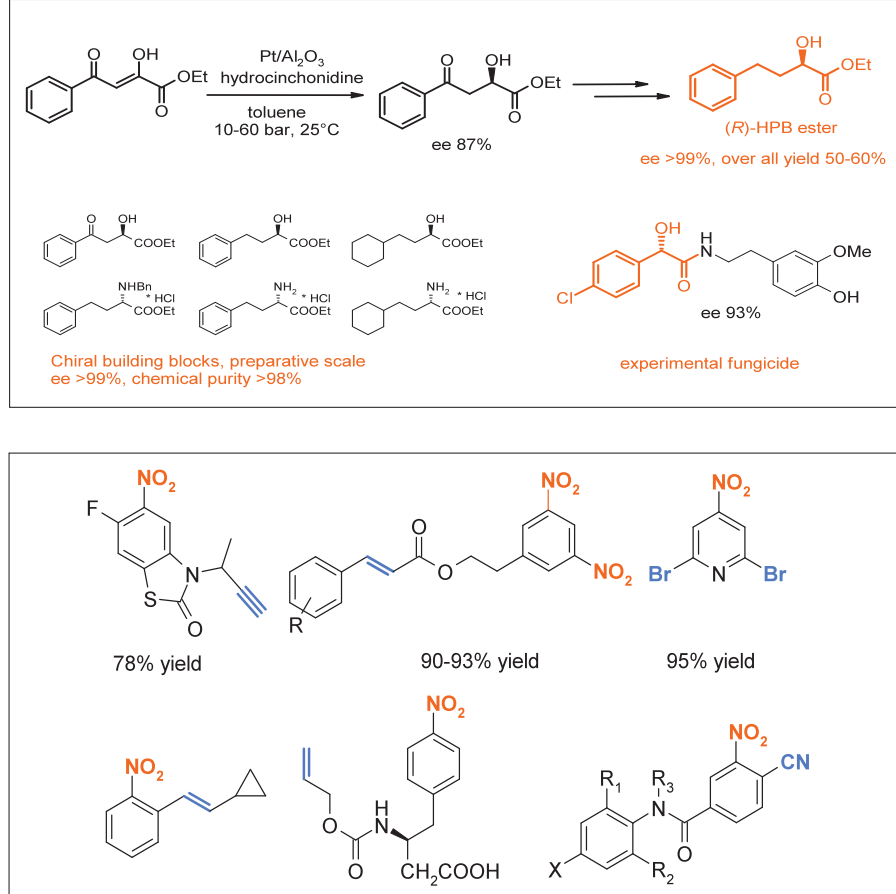

$92 \%$ yield

$73 \%$ yield

$58-94 \%$ yield

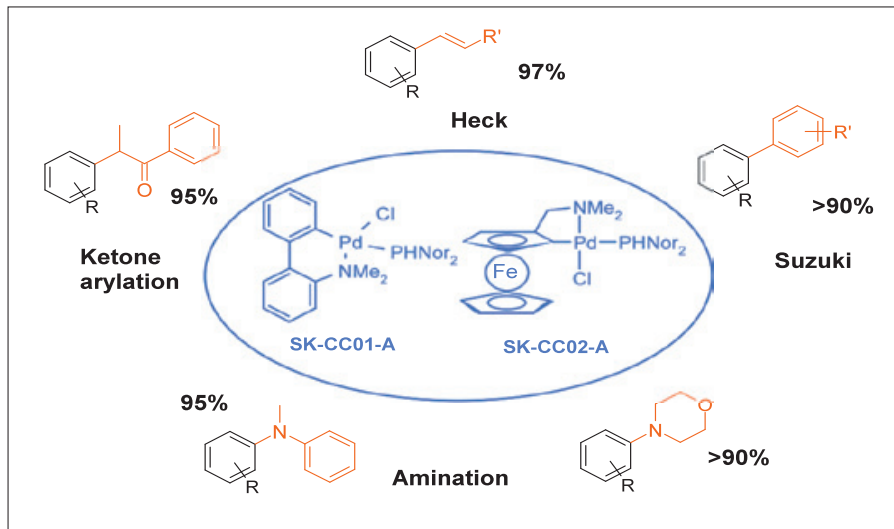

Fig. 2. Scope of the SK-CC catalysts for the preparation of substituted aryl building blocks.
Scheme 2. Technical applications of cinchona-modified $\mathrm{Pt}$ catalysts.

Fig. 1. Selected examples for the chemoselective hydrogenation functionalized $\mathrm{Pt} / \mathrm{C}-\mathrm{H}_{3} \mathrm{PO}_{2}-\mathrm{V}$ catalys (reducible functions in blue).

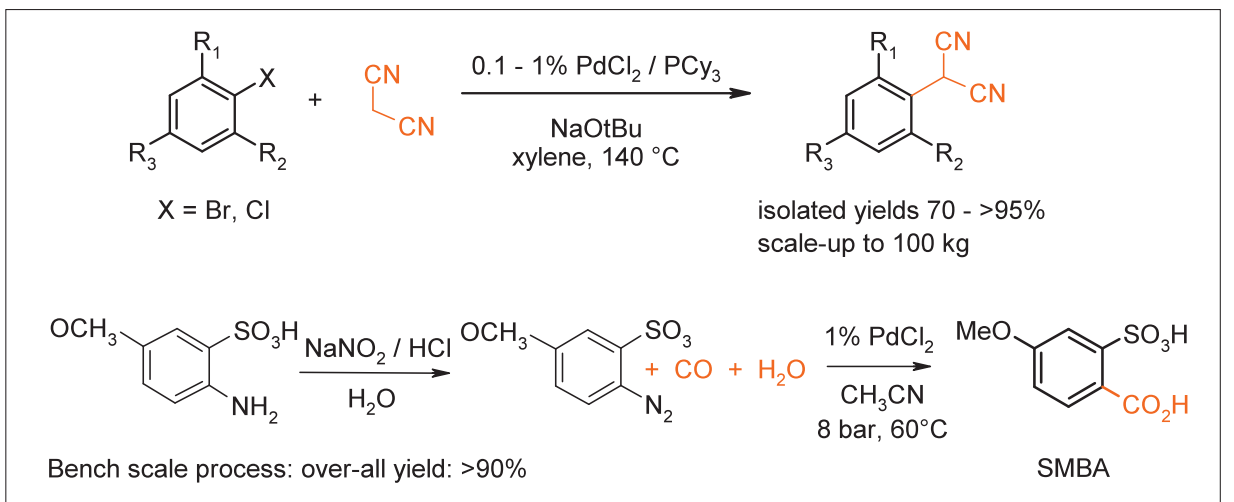

Scheme 3. Industrial processes using Pd coupling catalysts.

$(R)$-HPB ester, key intermediate for the socalled PRIL family of ACE inhibitors ${ }^{[7]}$ as well as related chiral building blocks. ${ }^{\left[{ }^{[8]}\right.}$ In this case an $\alpha, \gamma$-diketo ester was used as starting material which resulted in slightly lower enantioselectivities compared to $\alpha$ keto esters but since the keto hydroxy esters could be recrystallized, products with high 

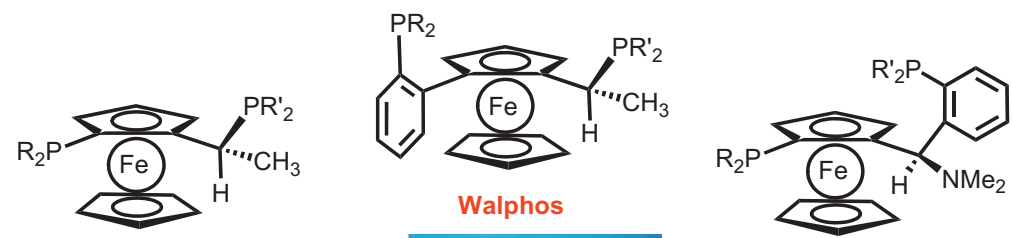

Josiphos

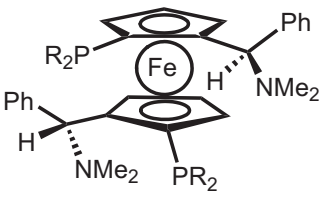

Mandyphos
Walphos
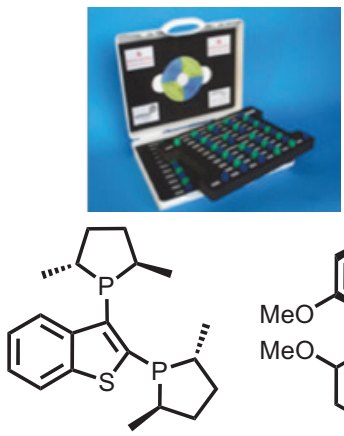

Taniaphos

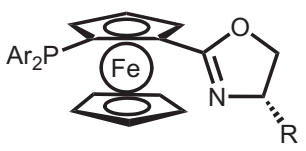

Naud Catalyst

Fig. 3. The Solvias Ligand Kit.

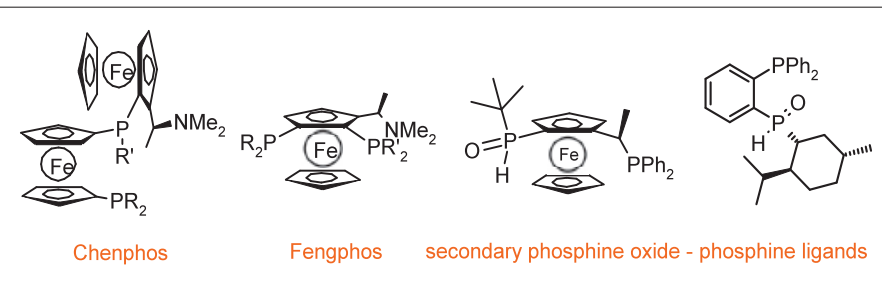

Fig. 4. Structures of selected experimental ligands.
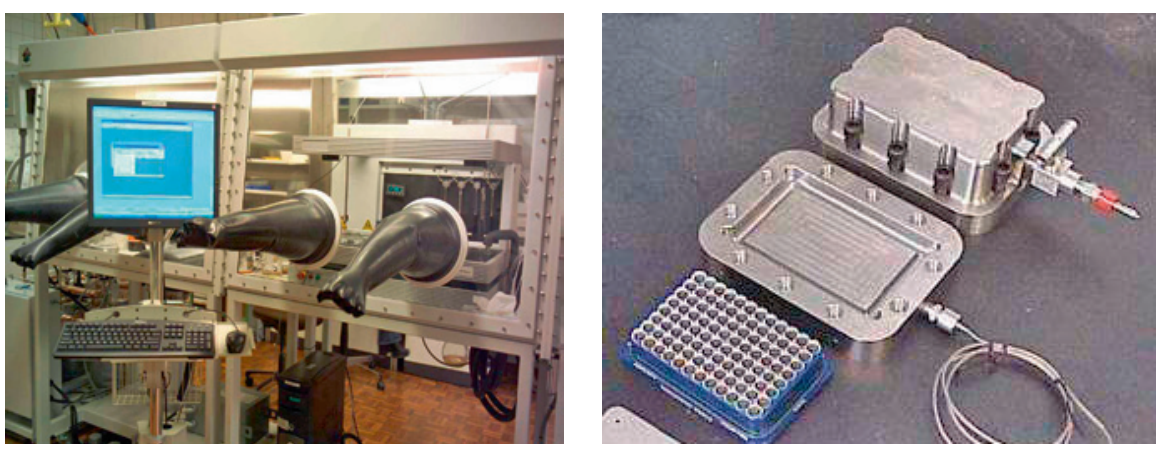

Fig. 5. Symyx HTS system: Inert glove box and 96-well plate.

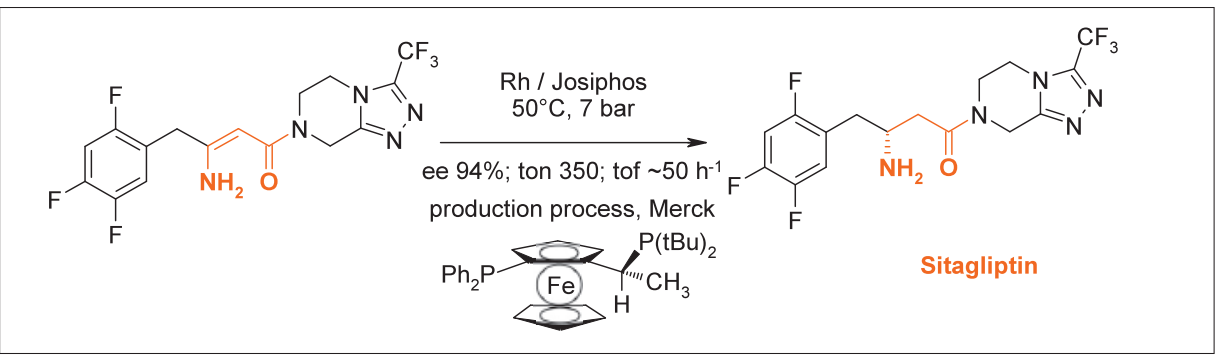

Scheme 4. Rh-Josiphos catalyzed process for Sitagliptin.

a catalyst for the production of $(S)$-metolachlor. ${ }^{[18]}$ This process is currently the largest enantioselective catalytic process and Ir-Josiphos is the most active and productive enantioselective catalyst developed to date. This achievement has motivated us to continue to develop new chiral ligands, efficient screening methods and to apply our knowhow to solve 'real-world' problems for our customers.
While there are now literally thousands of chiral ligands known in the literature only very few have ever been made on a larger scale and even fewer are available commercially in technical volumes. ${ }^{[19]}$ In recent years, Solvias has arguably developed the most comprehensive portfolio of chiral phosphine families which are available for screening (Solvias Ligand Kit; see Fig. 3) as well as for production purposes on a scale up to $100 \mathrm{~kg}$. ${ }^{20]}$

Furthermore, a number of experimental ligands such as Chenphos ${ }^{[21]}$ and Fengphos $^{[22]}$ (Fig. 4) are currently under development which are regularly included in the HT screening for customer problems but which up to now have only scaled to multi grams. Another exciting development is the finding that ligands containing secondary phosphine oxide and phosphine groups have very interesting catalytic properties. ${ }^{[21]}$ This is a new class of modular and readily accessible ligands with an as yet unknown industrial potential.

Screening is at the heart of any industrial catalysis development. For this reason, screening strategies were developed and optimized already in the former Central Research Laboratories. This of course continued in Solvias and culminated at the beginning of 2006 in the acquisition of the Symyx HiP robot (Fig. 5). This proved to be a huge step forward for the application of the enantioselective hydrogenation methodology at Solvias. [23] The Symyx technology with the appropriate analytics can handle up to 96 reactions per day with pressures up to 100 bar. Together with a library of around 600 chiral ligands the new approach has proven to be highly efficient and in the last two years $>100$ projects have been carried out. The hit rate for finding solutions has increased from $50 \%$ to $>90 \%$ since the new equipment has been in operation, mainly due to the ability to perform three times more experiments compared to more classical parallel reactors.

Among the many customer projects where Solvias catalysts have been successful but which we cannot describe for confidentiality reasons, two cases of efficient production processes are presented dealing with rather difficult substrates and which have been implemented on multi-tonne scales. The first example is the Rh-Josiphos catalyzed hydrogenation of an unprotected dehydro $\beta$-amino acid as depicted in Scheme 4 which is the key step of a new synthesis for Sitagliptin, a DPP-IV inhibitor for the treatment of type 2 diabetes, now being marketed by Merck. To find a solution for this unprecedented reaction the screening of dozens of ligands and additives was required, carried out in a collaborative effort both at Merck and Solvias. ${ }^{[23,24]}$

The second example is the Rh-Walphos catalyzed hydrogenation of the sterically 


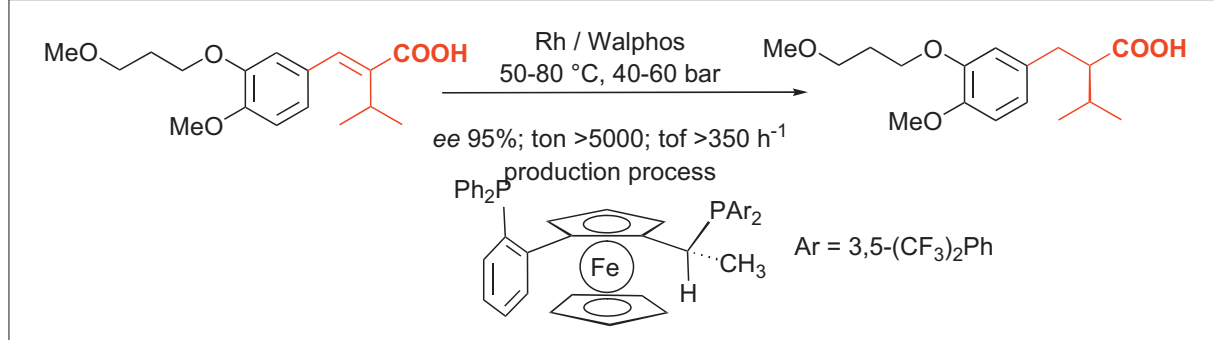

Scheme 5. Rh-Walphos catalyzed process for an Aliskiren building block.

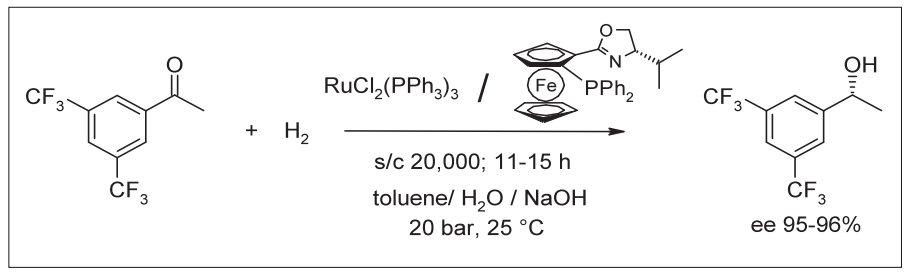

Scheme 6. Pilot process for the reduction of BTMA.

hindered $\alpha, \beta$-unsaturated acid shown in Scheme 5, a precursor of synthon A for the total synthesis of the renin inhibitor Aliskiren (Speedel/Novartis) originally developed by Solvias. The Rh-Walphos catalyst is easy to handle and achieves high turnover numbers and high $e e$ values. [25]

The last example briefly described is the development of a pilot process for the enantioselective hydrogenation of 3,5-bistrifluoromethyl acetophenone (BTMA) using a $\mathrm{Ru}$-phosphine-oxazoline complex in toluene in presence of aqueous $\mathrm{NaOH}$ (see Scheme 6) carried out in collaboration with Rohner AG. ${ }^{[26]}$ Within just two months, various reaction parameters and quality risk factors such as ligand structure, substrate quality, reaction conditions, thermal safety etc. were investigated and optimized. The reaction was carried out twice on a $140 \mathrm{~kg}$ scale at 20 bar and $25^{\circ} \mathrm{C}$ with substrate to catalyst ratios of 20,000 with an enantiomeric excess of $>95 \%$. After crystallization, (R)-3,5-bistrifluoromethyl phenyl ethanol (BTMP) was obtained with an ee between 97.7 and $98.6 \%$ in $70 \%$ chemical yield.

\section{Some Final Comments}

This short account shows that catalysis is indeed a valuable technology to not only produce simple bulk chemicals but that it is also applicable to the synthesis of complex, multifunctional molecules for the life science industry. We are convinced that the three methodologies described above will be able to successfully compete against other synthetic methods. On the other hand, it is also clear that it will require continuous efforts to remain competitive in this rapidly developing area of synthetic methodology and Solvias has every intention of doing so.

\section{Acknowledgments}

I thank my former and present colleagues mentioned in the references as well as the technical staff who have worked in the various projects with unrivalled skill and dedication and who deserve all the credit for the many outstanding results.

Received: December 18, 2009

[1] For a more detailed discussion see a) H. U. Blaser, Catalysis Today 2000, 60, 161; b) H. U. Blaser, Chem. Comm. 2003, 293.

[2] For a review see C. Exner, A. Pfaltz, M. Studer, H. U Blaser, Adv. Synth. Catal. 2003, 345, 1253.

[3] For a review see H. U. Blaser, H. Steiner, M. Studer, Chem CatChem, 2009, 1 , in print.

[4] For an overview see H. U. Blaser, M. Studer, Acc. Chem. Res. 2007, 40, 1348.

[5] M. Studer, S. Burkhardt, H. U. Blaser, Chem. Comm. 1999, 1727.

[6] M. Studer, H. U. Blaser, S. Burkhardt, Adv. Synth. Catal. 2002, 344, 511

[7] P. Herold, A. F. Indolese, M. Studer, H. P. Jalett, U. Siegrist, H. U. Blaser, Tetrahedron 2000, 56, 6497; M. Studer, S. Burkhardt, A. F. Indolese, H. U. Blaser, Chem. Comm. 20001327.

[8] H. U. Blaser, S. Burkhardt, H. J. Kirner, T. Mössner, M. Studer, Synthesis 2003, 1679.

[9] F. Cederbaum, C. Lamberth, C. Malan, F. Naud, F. Spindler, M. Studer, H. U. Blaser, Adv. Synth. Catal. 2004, 346, 842.

[10] P. Baumeister, H. U. Blaser, U. Siegrist, M. Studer, Chem. Ind. (Dekker) 1998, 75, 207; H. U. Blaser, U. Siegrist, H. Steiner, M. Studer, in 'Fine Chemicals through Heterogeneous Catalysis', Eds: R. A. Sheldon, H. van Bekkum, WileyVCH, Weinheim, 2001, p. 389.

[11] For an account see H. U. Blaser, A. F. Indolese, F. Naud, U. Nettekoven, A. Schnyder, Adv. Synth. Catal. 2004, 346, 1583.

[12] U. Nettekoven, F. Naud, A. Schnyder, H. U. Blaser, Synlett 2004, 2549.

[13] W. Mägerlein, A. F. Indolese, M. Beller, Angew. Chem. Int. Ed. 2001, 40, 2865.

[14] M. E. Limmert, A. J. Roy, J. F Hartwig, J. Org. Chem. 2005, 70, 9364; Q. Shen, J. F. Hartwig, J. Am. Chem. Soc. 2006, 128, 10028; Q. Shen, T. Ogata, J. F Hartwig, J. Am. Chem. Soc. 2008, $130,6586$.

[15] A. Schnyder, A. F. Indolese, T. Maetzke, J. Wenger, H. U. Blaser, Synlett 2006, 3167.
[16] U. Siegrist, T. Rapold, H. U. Blaser, Org. Process Res. Dev. 2003, 7, 429.

[17] B. D. Vineyard, W. S. Knowles, M. J. Sabacky, G. L. Bachmann, D. J. Weinkauff, J. Am. Chem. Soc. 1977, 99, 5946.

[18] H. U Blaser, H. P. Buser, K. Coers, R. Hanreich, H. P. Jalett, E. Jelsch, B. Pugin, H. D. Schneider, F. Spindler, A. Wegmann, Chimia 1999, 53, 275; H.U. Blaser, Adv. Synth. Catal. 2002, 344, 17.

[19] H. U. Blaser, M. Thommen, in 'Trivalent Phosphorus Compounds in Asymmetric Catalysis: Synthesis and Applications', Ed. A. Börner, Wiley-VCH, 2008, p. 1457.

[20] H. U. Blaser, B. Pugin, F. Spindler, M. Thommen, Acc. Chem. Res. 2007, 40, 1240

[21] W. Chen, B. Pugin, Solvias AG, unpublished results.

[22] X. Feng, B. Pugin, B. Gschwend, F. Spindler, M. Paas, H. U. Blaser, ChemCatChem, 2009, in print.

[23] H. U. Blaser, G. Hoge, M. Lotz, U. Nettekoven, A. Schnyder, F. Spindler, Chimia 2008, 62, 476.

[24] K. B. Hansen, Y. Hsiao, F. Xu, N. Rivera, A Clausen, M. Kubryk, S. Krska, T. Rosner, B. Simmons, J. Balsells, N. Ikemoto, Y. Sun, F. Spindler, C. Malan, E. J. J. Grabowski, J. D. Armstrong III, J. Am. Chem. Soc. 2009, 131, 8798.

[25] T. Sturm, W. Weissensteiner, F. Spindler, Adv. Synth. Catal. 2003, 345, 160.

[26] F. Naud, C. Malan, F. Spindler, C. Rüggeberg, A T. Schmidt, H. U. Blaser, Org. Process Res. Dev. 2007, 11, 519 . 